\title{
Cone Beam CT Evaluation of Maxillary Sinus Septa Prevalence, Height, Location and Morphology in Children and an Adult Population
}

\author{
Kaan Orhan ${ }^{a, b}$ Basak Kusakci Seker ${ }^{c}$ Seçil Aksoy ${ }^{b}$ Hakan Bayindir ${ }^{c}$ \\ Atilla Berberoğluc Emre Seker ${ }^{\mathrm{d}}$ \\ a Department of Dentomaxillofacial Radiology, Faculty of Dentistry, Ankara University, Ankara, and \\ Departments of ${ }^{b}$ Dentomaxillofacial Radiology, ${ }^{c}$ Periodontology and ${ }^{d}$ Prosthetic Dentistry, Faculty of Dentistry, \\ Near East University, Mersin, Turkey
}

\section{Key Words}

Maxillary sinus septa $\cdot$ Cone beam computed tomography • Maxillary sinus surgery $\cdot$ Dental implants

\begin{abstract}
Objective: The purpose of this study was to determine the prevalence, height, location and morphology of maxillary sinus septa in dentate, partially dentate and edentulous adults as well as in mixed dentition children using cone beam computed tomography (CBCT) for maxillary sinus surgical interventions. Subjects and Methods: Five hundred and fifty-four sides in the CBCT scans of 272 patients (30 children and 242 adults) were retrospectively analyzed. The prevalence, location and morphology were assessed in axial, sagittal, cross-sectional and panoramic 3-dimensional images. The height of septa was measured with the angle between the direction of the septum and median palatine suture. The differences among age, localization and measurements were statistically analyzed. Results: The prevalence of maxillary sinus segments with septa was $58 \%$. There were a total of $13(3.2 \%)$ septa of completely edentulous (CE), 198 (53.9\%) septa of edentate and 14 (3.8\%) septa of the mixed dentition maxillary segments. The location of septa observed in all study groups demonstrated a greater
\end{abstract}

prevalence $(69.1 \%)$ in the middle region than in the anterior and posterior regions. No statistically significant differences were observed with regard to gender or age, for septum height $(p>0.05)$. However, maxillary sinus septa are higher in partially edentulous patients than edentate and CE ones $(p<0.05)$. Conclusion: Septa of various heights and courses developed in all parts of the maxillary sinus, therefore to prevent possible complications during sinus surgery, extensive evaluation with an appropriate radiographic technique was indispensable.

Copyright @ 2012 S. Karger AG, Basel

\section{Introduction}

The maxillary sinus in the adult consists of a pyramidshaped cavity in the facial skull with its base at the lateral nasal wall and its apex extending into the zygomatic process of the maxilla [1]. The proximity of the maxillary sinus to the alveolar crest can be enhanced by sinus pneumatization, as well as resorption of the alveolar ridge due to tooth extraction, trauma or pathology. At the edentate stage of life, the size of the maxillary sinus increases further, often filling a large part of the alveolar process, leaving sometimes only a paper-thin bone wall on the lateral

\section{KARGER \\ Fax +41613061234 \\ E-Mail karger@karger.ch}

www.karger.com
(C) 2012 S. Karger AG, Basel

1011-7571/13/0221-0047\$38.00/0

Accessible online at:

www.karger.com/mpp
Dr. Kaan Orhan

Department of Dentomaxillofacial Radiology

Ankara University, Faculty of Dentistry

TR-06500 Besevler, Ankara (Turkey)

Tel. +90 533866 2520, E-Mail call53@yahoo.com 
and occlusal sides. This process of pneumatization of the sinus varies greatly from person to person and even from side to side [2].

All the surgical interventions, such as endoscopic sinus surgery and sinus lift surgery, in the posterior maxillary region require detailed knowledge of maxillary sinus anatomy and possible anatomical variations. Detailed knowledge of the patient's morphological conditions allows exact planning of invasive surgery and helps to avoid complications [3-9]. The presence of anatomical variations within the maxillary sinus, such as septa, has been reported to increase the risk of sinus membrane perforation during the surgical sinus elevation procedure $[6,10-$ 12]. Maxillary sinus septa were first described by Underwood [13] in 1910 as the walls of cortical bone within the maxillary sinus; the shape has been described as an inverted gothic arch arising from the inferior or lateral walls of the sinus, and may even divide the sinus into two or more cavities. The etiology of antral septa has been the subject of several hypotheses by various authors $[6,7,14$, 15]. Krennmair et al. [7] further classified the septa into primary and secondary septa, with the primary septa arising from the development of the maxilla, whereas the secondary septa were said to arise from the irregular pneumatization of the sinus floor following tooth loss. Evaluation of the anatomical structures inherent to the maxillary sinus is crucial for the success of sinus surgical procedures. Therefore, an exact and definitive radiological assessment is necessary $[4,16]$. Dental panoramic radiography, computed tomography (CT) and cone beam computed tomography (CBCT) have all been used to identify the maxillary sinus septa $[4-9,14-18]$. CBCT is a technique that has been proposed for maxillofacial imaging during the last decade and was first reported on in the literature by Mozzo et al. [19]. In the last decade, CBCT has been recommended as an excellent, low-cost tool for the evaluation of these anatomical structures with only slightly more radiation than panoramic radiography and far less than a CT scan [20-23].

Despite various studies which were conducted on height, prevalence and morphology of the maxillary sinus septa in adult patients, only very few studies [24, 25] were found for populations of children. Moreover, no study was conducted in our population especially in the mixed dentition stage. Hence, it was considered worthwhile to determine the prevalence, height, location and morphology of maxillary sinus septa in dentate, partially dentate and edentulous adults as well as in mixed dentition children and adolescents using CBCT.

\section{Subjects and Methods}

The study was based on a retrospective evaluation of CBCT scans of 272 subjects (152 females, 120 males). In adult patients, CBCTs were taken for dental implant surgery, impacted third molar surgery or various cystic surgical operations in jaws while in children CBCTs were taken for the evaluation of impacted teeth and various cystic changes around impacted teeth. Our study population consisted of children in the mixed dentition stage (30 patients) and adult patients (242 patients).

The age range of the adult population was $17-83$ years whereas that of the children was 6-10 years. Each right and left maxillary sinus was defined as segment. A total of 544 maxillary sinus segments were evaluated with CBCT.

The patient consent forms were prepared according to the principles of the Helsinki Declaration, including all amendments and revisions. The Institutional Review Board and the Ethics Committee reviewed and approved the informed consent form. Informed consent forms showed that the radiographs could be used for scientific studies. The consent forms were signed by the patients or their legal guardians. Subjects with evidence of current orthodontic treatment for erupted or supernumerary teeth overlying maxillary sinus septa or bone disease were excluded from the study.

CBCT scans were obtained using a Newtom 3G (Quantitative Radiology s.r.l., Verona, Italy). All images were recorded at 120 $\mathrm{kVP}$ and 3-5 mA using a 9-inch field of view, an axial slice thickness of $0.3 \mathrm{~mm}$ and isotropic voxels. The evaluations of maxillary sinus septum morphology, location and prevalence were done in axial, sagittal, cross-sectional and reconstructed panoramic images while 3-dimensional reconstructions were used as necessary (fig. 1). To avoid any errors in the localization of septa, the multiplanar reconstruction technique was used. Each maxillary sinus bearing a septum was divided into three portions: anterior $=$ mesial to distal aspect of second premolar; middle = distal aspect of second premolar to distal aspect of second molar, and posterior $=$ distal aspect of second molar. All examinations and measurements were done by a 12-year experienced oral and maxillofacial radiologist (K.O.). To detect the course and to measure the exact height of the septa in the sinus, 1-mm reconstructed panoramic images were used. The heights of the septa were measured in three regions along the course of the septa across the sinus floor: the lateral, middle and medial aspects based on previous studies [4, 5] (fig. 2). The mean of these measurements was set as the final measurement. Meanwhile, the angle between the direction of the septum and median palatine suture was also measured using axial images (fig. 2). All measurements were accomplished with software programmed for an automated image measuring tool. All measurements were done 3 times by the same observer (K.O.). The same observer also performed the study twices with an interval of 2 weeks in order to detect intraobserver variability. Statistical analyses were carried out using the SPSS version 12.0.1 (SPSS, Chicago, Ill., USA) software program. To assess intraobserver reliability, the Wilcoxon matched-pairs signed-ranks test was used for repeat measurements of the observer. Independent groups in the study were compared using the Mann-Whitney U test; the results were expressed as means \pm standard deviation. Nonparametric data were compared using the Kruskal-Wallis test. The Pearson $\chi^{2}$ test was performed for statistical analysis among gender, age, localization and measurements $(\mathrm{p}<0.05)$. 

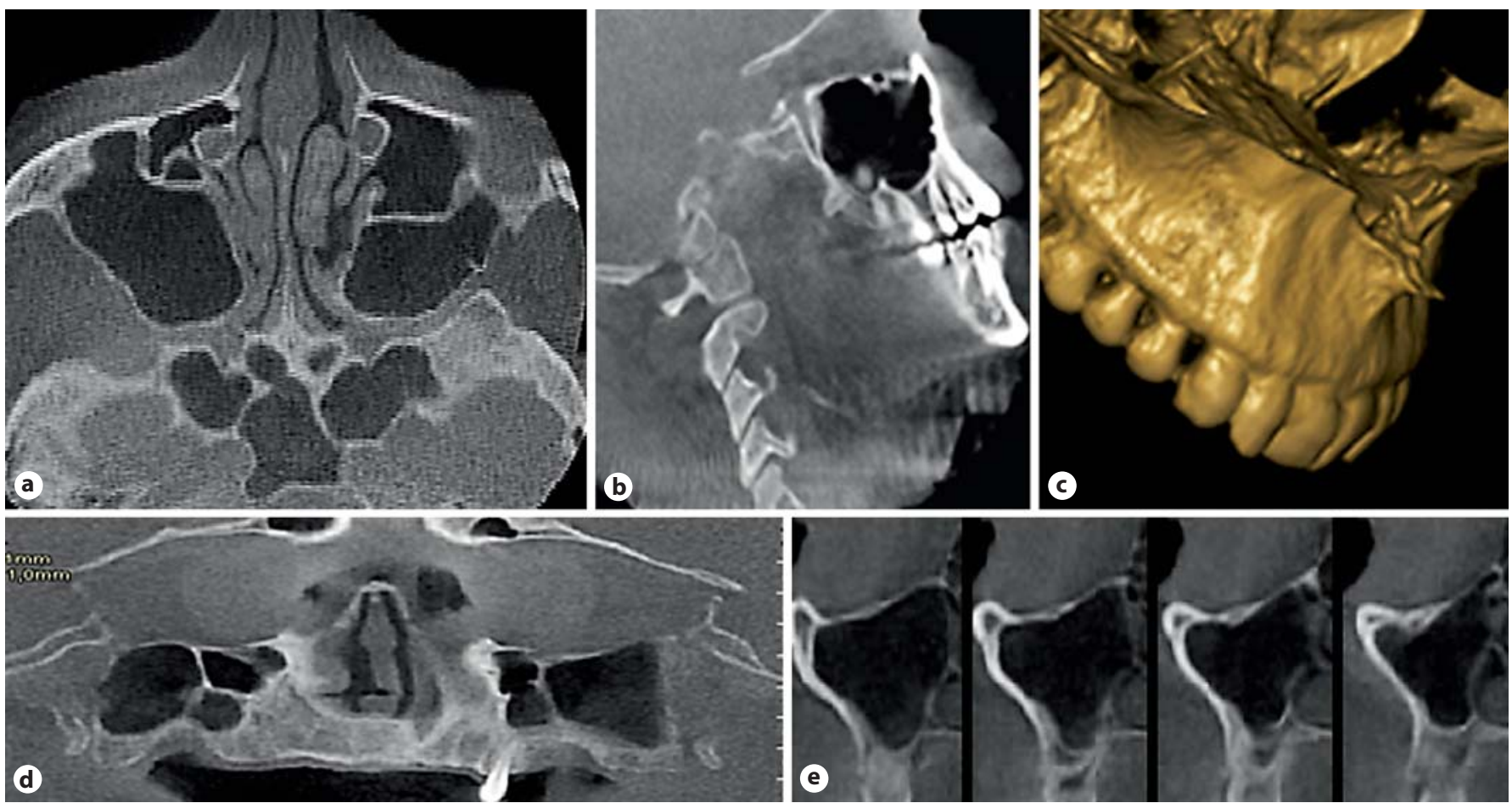

Fig. 1. Reconstructed axial (a), sagittal (b) and 3-dimensional (c) images, as well as panoramic (d) and crosssectional (e) CBCT images used for detection and measurement of maxillary sinus septa.

\section{Results}

The intraobserver consistency was rated at $96.9 \%$ between two measurements; hence there was no statistically significant difference between the two intraobserver measurements $(\mathrm{p}>0.05)$. The prevalence of maxillary sinus segments with septa was 58\% (316/544) in 228 patients (50\% in males and $44.8 \%$ in females). A total of 369 septa were found in the 544 maxillary segments. A hundred and sixty-six (44.9\%) septa were identified on the right side, whereas 203 (55\%) were on the left. There were a total of 13 (3.2\%) septa of completely edentulous (CE), 198 (53.9\%) septa of edentate and 14 (3.8\%) septa of the mixed dentition maxillary segments. Primary septa were detected in $85(23.3 \%)$ of the partially edentulous (PE) segments and there were also $59(16.2 \%)$ secondary septa in PE patients. Septa were found unilaterally in 148 segments (40.1\%) and bilaterally in 221 (59.8\%) segments.

Although unilaterally, septa were most common (12 cases; 3.25\%) in cases with mixed dentition, in patients with dentition bilaterally, septa were most frequently detected $(85 ; 23 \%)$. Unilaterally 2 septa were detected in 4 $(1.08 \%)$ CE cases, bilaterally 1 septum in $4(1.08 \%)$ cases, bilaterally 2 septa on one side and 1 septum on the other side in 1 case $(0.2 \%)$, unilaterally 3 septa in 2 individuals $(0.4 \%)$ and bilaterally 3 septa in 2 CE cases (0.4\%).

In the PE cases, septa were detected with the following distribution: unilaterally 1 septum was detected in 54 of $187(28.8 \%)$ cases, unilaterally 2 septa in $5(2.6 \%)$ individuals, bilaterally 1 septum in 45 (24\%) individuals, bilaterally 2 septa in $2(1 \%)$ cases, bilaterally 2 septa on one side and 1 septum on the other side in 26 individuals (13.9\%), unilaterally 3 septa in 2 individuals (2\%), bilaterally 3 septa on one side and 1 septum on the other side in 5 individuals (2.6\%), bilaterally 3 septa on one side and 2 septa on the other side in 2 patients (1\%) were detected (table 1).

Analysis of the anatomical location of the septa within the sinus revealed that $45(12.2 \%)$ septa were located in the anterior region, $254(69.1 \%)$ in the middle region and 70 (18.6\%) in the posterior region. The location of septa observed in all study groups demonstrated a greater prevalence $(69.1 \%)$ in the middle region than anterior and posterior regions (table 2). Measurements of the height of each individual septum varied among different regions. Comparison between the average septum measurements of $\mathrm{PE}$ and $\mathrm{CE}$ regions demonstrated statistically significantly 
Fig. 2. a The points related to the septal height measurements medial (arrow a), middle (arrow b) and lateral (arrow c) in axial CBCT images. b Reconstructed panoramic images also showing the vertical dimension of the antral septa at three positions. c Image showing the measurement of the angle between the direction of the septum and median palatine suture.
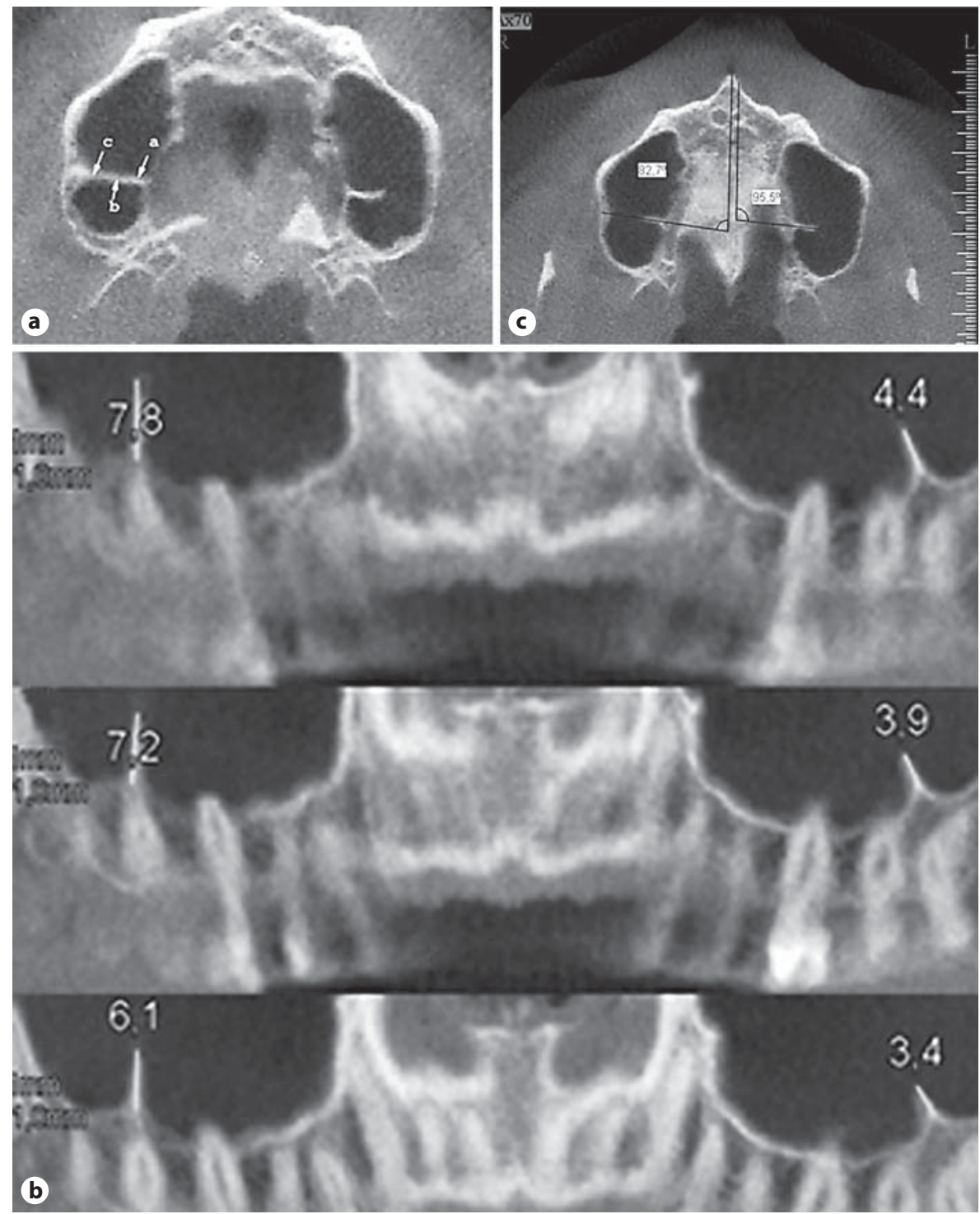

higher values at all points of measurement $(p<0.05)$ than other areas. Separation of septa found in PE areas into those located apically to remaining teeth (primary septa) and those in the proximity of edentulous areas (other septa) showed that there was no statistically significant difference between the heights of the septa in groups ( $p>0.05)$. On the other hand, primary septa in PE demonstrated statistically higher values compared with CE regions (table 2).

The mean height of septa for males was $4.86 \pm$ $2.01 \mathrm{~mm}$, for females $5.02 \pm 2.14 \mathrm{~mm}$ while the mean height for children and adult patients was $4.33 \pm 1.92$ and $5.5 \pm 2.64 \mathrm{~mm}$, respectively. The range of the septa in the study group was $1-10.3 \mathrm{~mm}$ for males and $2-15 \mathrm{~mm}$ for female patients. There were no statistically significant differences among the height values of maxillary sinus septa, with regard to gender or age ( $p>0.05)$. Moreover, the angle of the septum in the anterior maxillary sinus region ranged from 34.1 to $90.6^{\circ}$, with a mean of $62.2 \pm$ $15.05^{\circ}$, the angle of the septum within the middle region ranged from 44.8 to $118^{\circ}$, with a mean of $75.8 \pm 18.6^{\circ}$, and the angle of the septum in the posterior maxillary sinus region ranged from 58.1 to $123.6^{\circ}$, with a mean of $90.75 \pm 19.4^{\circ}$ (table 2). Significant differences in the angle of the septum were noted between the anterior maxillary sinus region and posterior region $(\mathrm{p}<0.05)$. All detected septa showed a mediolateral orientation. 
Table 1. Distribution of septa in maxillary sinus segments

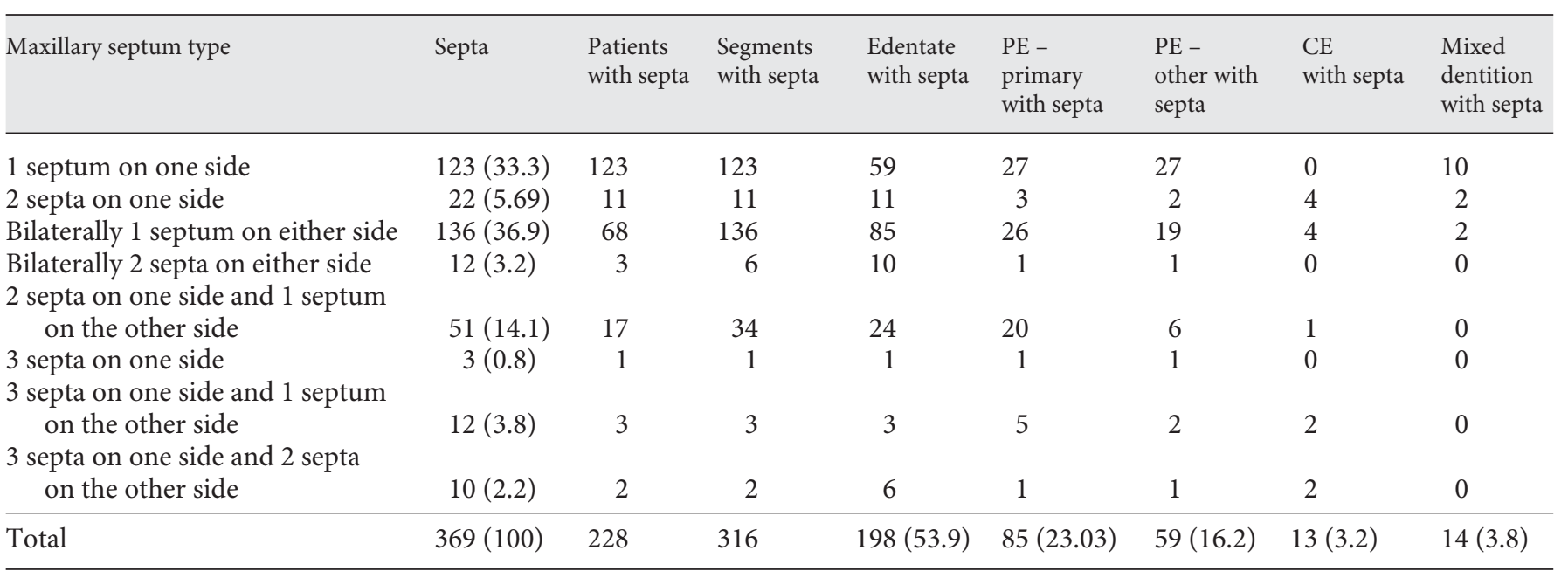

Results are expressed as numbers with percentages in parentheses.

Table 2. Summary of septum location, height and angle measurements according to dental status

\begin{tabular}{|c|c|c|c|c|c|c|c|c|}
\hline \multirow[t]{2}{*}{ Dental status } & \multicolumn{4}{|c|}{ Septum location, $\mathrm{n}$} & \multicolumn{3}{|c|}{ Mean septum height $\pm \mathrm{SD}, \mathrm{mm}$} & \multirow{2}{*}{$\begin{array}{l}\text { Mean septum } \\
\text { angle } \pm \mathrm{SD} \text {, } \\
\mathrm{mm}\end{array}$} \\
\hline & anterior & middle & posterior & total & lateral & middle & medial & \\
\hline Edentate & 19 & 152 & 27 & $198(53.9)$ & $4.15 \pm 2.08$ & $4.85 \pm 2.38$ & $5.99 \pm 2.92$ & $74.75 \pm 17.73$ \\
\hline PE - primary & 10 & 49 & 26 & $85(23.03)$ & $3.18 \pm 3.39$ & $4.88 \pm 3.18$ & $6.54 \pm 3.27$ & $76.22 \pm 20.89$ \\
\hline $\mathrm{PE}$ - other & 10 & 40 & 9 & $59(16.2)$ & $4.54 \pm 3.87$ & $6.22 \pm 3.92$ & $7.09 \pm 4.11$ & $74.11 \pm 21.63$ \\
\hline $\mathrm{CE}$ & 3 & 7 & 3 & $13(3.2)$ & $4.70 \pm 1.82$ & $5.33 \pm 2.64$ & $6.88 \pm 3.42$ & $77.11 \pm 18.90$ \\
\hline Mixed dentition (children) & 3 & 6 & 5 & $14(3.8)$ & $4.12 \pm 2.88$ & $4.32 \pm 2.90$ & $4.55 \pm 2.88$ & $74.18 \pm 20.32$ \\
\hline Total & 45 (12.2) & $254(69.1)$ & $70(18.6)$ & $369(100)$ & $3.73 \pm 0.76$ & $5.12 \pm 0.88$ & $6.21 \pm 1.01$ & $75.29 \pm 19.89$ \\
\hline
\end{tabular}

Figures in parentheses indicate percentages.

\section{Discussion}

The $58 \%$ prevalence of septa in this study was higher than the $16-33 \%$ reported in previous studies $[4,6,7,13$, 26]. This difference could be attributed to the difference between the radiographic examinations. The higher prevalence in our study was based on the thin slice interval of CBCT images $(0.3 \mathrm{~mm})$. As for the location of the septa, a greater number of incidence was found in the middle regions while several studies $[6,7,26]$ had observed them in the anterior $[5,9,13]$ and in the posterior regions $[5,9]$. The morphology of septa did, however, demonstrate significant variability. This is evident in the results obtained from measuring each septum at 3 aspects along its medial-lateral dimension. These differences could be due to comparing septa from totally edentulous areas with septa from PE ones $[4,6,7,9]$. However, our results were contrary to these as the mean height of septa in CE cases was higher than both septum types of $\mathrm{PE}$ cases but is similar to the results which were obtained by Koymen et al. [5].

Previous studies reported different heights for the septa ranging from 5.6 to $20.6 \mathrm{~mm}[5,7,9,13,24-26]$ in other populations. However, the mean adult septum height of our study was lower than those of some other populations $[4,6,7,13,24]$. 
The probable reason for the differences is that Neugebauer et al. [24] did not make any distinction between children and the adult population in their study while Naitoh et al. [25] examined only dry skulls of children.

As surgery involving the maxillary sinus segment is applied more frequently, radiological evaluation determining the sizes and localizations of the septa has gained importance. The panoramic radiographs and the CT scans are the most frequently used radiological methods for planning dental implants $[6,7,15]$. When comparing incidence of septa in both radiological techniques, several authors have observed false-negative results in the panoramic radiographs $[6,7,14]$. Some authors have had results with 50\% false-negative findings [14].

Studies indicate that CT scans are more reliable than panoramic radiographs in the preoperative analysis. Today, CT can be performed in axial and coronal planes with 3-dimensional views for diagnosis and treatment of this region $[27,28]$. The 3 -dimensional CT avoids the superimposition and problems due to magnification and offers to visualize the craniofacial structures with more precision than the 2-dimensional conventional methods. Despite these advantages, the effective dose of CT is much higher than that of the conventional radiographs and also an expensive procedure, and scanners are not easily accessible $[22,23]$.

In the last decade, a technique called CBCT was proposed for maxillocraniofacial imaging [19]. The comparison of absorbed doses shows that the CBCT is similar to dental panoramic radiology, which has requirements that are considerably lower than medical CT imaging [21-23]. The effective dose (ICRP 2007) from a standard dental protocol scan using a traditional CT was 1.5-12.3 times greater than comparable medium field of view dental CBCT scans [23]. It was also stated that the image quality of CBCT was adjudged to be equivalent to that of tradi- tional CT for visualizing the maxillofacial structures. Moreover, beam-hardening artifacts due to dental-care material and implants were weaker at CBCT than at multislice CT [29]. From the radiation point of view, CBCT examinations can be used instead of CT in order to evaluate anatomical structures like the maxillary sinus.

There are limited studies examining children's septa $[24,25]$ that have been published. With the advent of endoscopic sinus surgery in adults, studies were initiated to evaluate its safety and efficacy in children. Precise knowledge of the children's maxillary sinus septum morphology is important and allows exact planning of endoscopic sinus surgery and helps to avoid complications. It should be noted that maxillary septa also exist in children. The height of these maxillary septa was similar to those of adult patients without a significant difference in this study. The prevalence of septa has no relation with the patient's gender or age, but there are differences based on the type of edentulism. Differences between the results obtained from different studies may reflect variability between methods of measurement, tools utilized to gather data, and variation among populations studied [24-30].

\section{Conclusion}

Septa of various heights and courses developed in all parts of the maxillary sinus; therefore, to prevent possible complications during sinus surgery, extensive evaluation with an appropriate radiographic technique is indispensable. CBCT was a powerful tool for the examination of this zone capable of making measurements and 3-dimensional representations of the region with less ionizing radiation.

\section{References}

1 McGowan DA, Baxter PW, James J: The Maxillary Sinus and Its Dental Implications. Oxford, Wright, Butter-Worth-Heinemann, 1993, pp 1-125.

-2 Boyne PJ, James RA: Grafting of the maxillary sinus floor with autogenous marrow and bone. J Oral Surg 1980;38:613-616.

-3 González-Santana H, Peñarrocha-Diago M, Guarinos-Carbó J, Sorní-Bröker M: A study of the septa in the maxillary sinuses and the subantral alveolar processes in 30 patients. J Oral Implantol 2007;33:340-343.
-4 Kim MJ, Jung UW, Kim CS, Kim KD, Choi SH, Kim CK: Maxillary sinus septa: prevalence, height, location and morphology. A reformatted computed tomography scan analysis. J Periodontol 2006;5:903-908.

5 Koymen R, Gocmen-Mas N, Karacayli U, Ortakoglu K, Ozen T, Yazici AC: Anatomic evaluation of maxillary sinus septa. Surgery and Radiology Clin Anat 2009;22:563-570.

-6 Krennmair G, Ulm C, Lugmayr H: Maxillary sinus septa: incidence, morphology and clinical implications. J Craniomaxillofac Surg 1997;25:261-265.
-7 Krennmair G, Ulm GW, Lugmayr H, Solar P: The incidence, location, and height of maxillary sinus septa in the edentulous and dentate maxilla. J Oral Maxillofac Surg 1999;57: 667-771.

$>8$ Naitoh M, Suenaga Y, Kondo S, Gotoh K, Ariji E: Assessment of maxillary sinus septa using cone-beam computed tomography: etiological consideration. Clin Implant Dent Relat Res 2009;11(suppl 1):52-58. 
$>9$ Velasquez-Plata D, Hovey LR, Peach CC, Alder ME: Maxillary sinus septa: a 3-dimensional computerized tomographic scan analysis. Int J Oral Maxillofac Implants 2002;17: 854-860.

10 Betts NJ, Miloro M: Modification of the sinus lifts procedure for septa in the maxillary antrum. J Oral Maxillofac Surg 1994;52:332333.

11 Chanavaz M: Maxillary sinus: anatomy, physiology, surgery, and bone grafting related to implantology - eleven years of surgical experience. J Oral Implantol 1990;16:199209.

$\checkmark 12$ Van den Bergh JP, ten Bruggenkate CM, Disch FJ, Tuinzing DB: Anatomical aspects of sinus floor elevations. Clin Oral Implants Res 2000;11:256-265.

13 Underwood AS: An inquiry into the anatomy and pathology of the maxillary sinus. J Anat Physiol 1910;44:354-369.

14 Kasabah S, Slezak R, Simunek A, Krug J, Lecaro MC: Evaluation of the accuracy of panoramic radiograph in the definition of maxillary sinus septa. Acta Med 2002;45: 173-175.

15 Lugmayr H, Krennmair G, Holzer H: The morphology and incidence of maxillary sinus septa. Rofo 1996;165:452-454.

16 Abrahams JJ: Dental CT imaging: a look at the jaw. Radiology 2001;219:334-345.
Alder ME, Deahl ST, Matteson SR: Clinical usefulness of two dimensional reformatted and three-dimensionally rendered computerized tomographic images: literature review and a survey of surgeons opinions. J Oral Maxillofac Surg 1995;53:375-386.

18 Almog DM, Romano PR: CT-based dental imaging for implant planning and surgical guidance. NY State Dent J 2007;73:51-53.

19 Mozzo P, Procacci C, Tacconi A, Martini PT, Bergamo IA: A new volumetric CT machine for dental imaging based on the cone-beam technique: preliminary results. Eur Radiol 1998;8:1558-1564.

20 Liang X, Jacobs R, Hassan B, Li L, Pauwels R, Corpas L: A comparative evaluation of cone beam computed tomography (CBCT) and multi-slice CT (MSCT). I. On subjective image quality. Eur J Radiol 2010;75:265-269.

21 Loubele M, Bogaerts R, Van Dijck E, Pauwels R, Vanheusden S, Suetens P, Marchal G, Sanderink G, Jacobs R: Comparison between effective radiation dose of CBCT and MSCT scanners for dentomaxillofacial applications. Eur J Radiol 2009;71:461-468.

22 Ludlow JB, Davies-Ludlow LE, Brooks SL, Howerton WB: Dosimetry of 3 CBCT devices for oral and maxillofacial radiology: CB Mercuray, NewTom 3G and i-CAT. Dentomaxillofac Radiol 2006;35:219-226.

23 Ludlow JB, Ivanovic M: Comparative dosimetry of dental CBCT devices and 64-slice CT for oral and maxillofacial radiology. Oral Surg Oral Med Oral Pathol Oral Radiol Endod 2008;106:106-114.
24 Neugebauer J, Ritter L, Mischkowski RA, Dreiseidler T, Scherer P, Ketterle M, Rothamel D, Zöller JE: Evaluation of maxillary sinus anatomy by cone-beam CT prior to sinus floor elevation. Int J Oral Maxillofac Implants 2010;25:258-265.

25 Naitoh M, Suenaga Y, Gotoh K, Ito M, Kondo $\mathrm{S}$, Ariji E: Observation of maxillary sinus septa and bony bridges using dry skulls between Hellman's dental age of IA and IIIC. Okajimas Folia Anat Jpn 2010;87:41-47.

26 Ulm CW, Solar P, Krennmair G, Matejka M, Watzek G: Incidence and suggested surgical management of septa in sinus-lift procedures. Int J Oral Maxillofac Implants 1995; 10:462-465.

27 Zinreich JS, Benson LM, Oliverio JP: Sinonasal cavities: CT normal anatomy, imaging of the osteomeatal complex and functional endoscopic surgery; in Som PM, Curtin HD (eds): Head and Neck Imaging, ed 3. St Louis, Mosby, 1996, p 98.

28 Kumar V, Ludlow JB, Mol A, Cevidanes L: Comparison of conventional and cone beam CT synthesized cephalograms. Dentomaxillofac Radiol 2007;36:263-269.

29 Carrafiello G, Dizonno M, Colli V, Strocchi S, Pozzi Taubert S, Leonardi A: Comparative study of jaws with multislice computed tomography and cone-beam computed tomography. Radiol Med 2010;115:600-611.

30 Jensen OT, Shulman LB, Block MS, Iacono VJ: Report of the Sinus Consensus Conference of 1996. Int J Oral Maxillofac Implants 1998;13:11-12. 